\title{
SUICÍDIO E MANEJO PSICOTERAPÊUTICO EM SITUAÇÕES DE CRISE: UMA ABORDAGEM GESTÁLTICA
}

\author{
Suicide and interventions in crisis: A Gestalt-therapy approach \\ Suicidio y del manejo y de las intervenciones em situaciones de crisis: La Gestalt-terapia \\ Karina OKaJima FuKumitsu \\ Karen SCAVACINI
}

\begin{abstract}
Resumo: O suicídio é um gesto de comunicação e, ao mesmo tempo, de falta de comunicação, de recusa e de surpresa. $\mathrm{O}$ artigo tem como objetivo apresentar relações entre o suicídio e a Gestalt-terapia, bem como a compreensão dos mecanismos neuróticos e do manejo e das intervenções em situações de conflito e crise experienciados pela pessoa que percebe, no suicídio, uma alternativa para eliminar seu desespero e sofrimento. Além disso, pretende-se incentivar a discussão do tema e suas repercussões nas lides acadêmicas, principalmente nos cursos que lidam com o humano, pois se trata dos aspectos relacionados à vida, e o profissional, ao deparar com o desespero existencial do cliente, pode perceber sua falta de instrumentalização para manejar situações de crise. O conflito, segundo o aporte gestáltico, é configurado como um distúrbio do campo e significa a possibilidade de crescimento, uma vez que oferece ao indivíduo o confronto com novas figuras.
\end{abstract}

Palavras-chave: Suicídio; Intervenção na Crise; Prevenção do suicídio; Gestalt-terapia.

\begin{abstract}
The suicide is a communication gesture and, in the same time, is a lack of communication, and it is a denial and a surprise. This article has a purpose of establish relationship between suicide and the Gestalt approach, as well, to comprehend the neurotic mechanism and the interventions in crisis situations. The person who thinks about the suicide maybe wants to eliminate his despair and suffering. Besides this, it is intended to promote the discussion of this theme and its impact in the academic environment, especially in courses that work with human beings. The conflict, according Gestalt approach is a field disturbances and it means the potential for growth, because offers to the organism o confrontation among new figures.

Keywords: Suicide; Crisis Intervention; Suicide prevention; Gestalt-therapy.
\end{abstract}

Resumen: El suicidio es un gesto de comunicación y, a la vez, de falta de comunicación, de recusa y de sorpresa. El artículo tiene como objetivo presentar relaciones entre el suicidio y la Gestalt-terapia, así como la comprensión de los mecanismos neuróticos y del manejo y de las intervenciones en situaciones de conflicto y crisis experimentadas por la persona que percibe, en el suicidio, una alternativa para eliminar su desesperación y sufrimiento. Además de eso, se pretende incentivar la discusión del tema y sus repercusiones en las lides académicas, principalmente en los cursos que lidian con el humano, porque se trata de los aspectos relacionados a la vida, y el profesional, al depararse con el desespero existencial del cliente, puede percibir su falta de instrumentalización para manejar situaciones de crisis. El conflicto, según el aporte gestáltico, se configura como un disturbio del campo y significa la posibilidad de crecimiento, puesto que ofrece al individuo el confronto con nuevas figuras.

Palabras clave: Suicidio; Intervención en la crisis; Prevención do suicidio; Gestalt-terapia.

\section{Introdução}

O suicídio é um duelo entre o assassino e o assassinado que se encontram no ato da morte. Qual é o significado do ato de se matar? Finalizar um sofrimento e/ou um ato de desespero? Representaria uma falta de sentido de vida? Uma retroflexão? Projeção? Confluência? Um assassinato? A solução para um problema? Muitas perguntas para poucas respostas. O fato é que na lida com o suicídio nunca se terão todas as explicações e respostas para a vastidão das incertezas que abrangem a dicotomia entre a escolha da vida ou da morte.

Acreditamos, porém, que o suicídio é multicausal, não pode ser compreendido somente por uma faceta e, na maioria dos casos, existe uma interação entre fatores psicológicos, psiquiátricos, econômicos, culturais, religiosos que deve ser levada em consideração. No presente estudo abordaremos a faceta psicológica, mais especificamente, segundo o aporte da Gestalt-terapia. É necessário apresentar a distinção entre as causas e o desencadeante. As causas são sempre múltiplas, no entanto, há, geralmente, algo que desencadeia o ato, como a perda de um emprego, que faz aflorar alguma coisa que já estava no fundo e que tem relação com mais variáveis.

Como o fogo: relva seca e fortes ventos podem permanecer apenas como possibilidades perigosas, elementos de combustão. Mas, se um raio cai nessa relva, a chance de o fogo aumentar será rápida: pula de leve para intensa (Jamison, 2010, p. 183). 
Se o suicídio é uma fuga no sentido de que a pessoa que o comete foge do sofrimento e, conforme as palavras de Perls (1975/1988, p. 35), "nem todo contato é saudável, nem toda fuga é doentia”, é importante considerar as seguintes indagações: Fuga do quê? Para quê? Por quanto tempo? Isso posto, o presente artigo não ofertará todas as respostas, tampouco não será apresentado um modelo único de atuação; terá, sim, a intenção de provocar reflexões (e talvez mais questões sem respostas), a fim de compartilhar, quais intervenções e manejos nos atendimentos a sujeitos que tentaram o suicídio, que pensam em suicídio, bem como com sobreviventes que vivenciam o luto provocado pela morte de alguém querido por suicídio.

A expectativa é que, depois de tentar cometer suicídio, o indivíduo vá repetir o ato nos próximos meses (Chiles \& Strosahl, 2004). Dessa maneira, no caso daqueles que tentaram o suicídio, é necessário fortalecer os fatores protetores e minimizar os fatores de risco, a fim de que a tragédia pessoal e familiar não se apresente como uma situação permanente, ou seja, que o suicídio não seja efetivamente consumado. Salienta-se que, na avaliação dos níveis de riscos, cada tentativa prévia é categorizada como um alto fator de risco a quem quer se matar e, quanto mais tentativas, maior o risco. Outros fatores são: a presença de uma ideação suicida frequente, intensa e duradora - na qual a pessoa apresenta um plano específico para sua morte, com acesso a um método letal (Beck, Resnik \& Lettieri, 1974) - e quando há evidências de comprometimento no autocontrole, disforia grave, baixa autoestima e falta de confiança em si.

Acredita-se que, em muitos casos, o suicídio possa ser prevenido e que, em situações de crise, ou seja, de alto risco para o suicídio, como as supracitadas, o profissional deverá tomar providências e cuidados no manejo clínico, estar receptivo, disponível e alerta ao estado de conflito e contatar familiares, médicos e/ou encaminhar para internação, se necessário.

\section{0 suicídio e a gestalt-terapia}

Trabalhar com o tema do suicídio inclui lidar com questões existenciais, tais como: falta de sentido, solidão, tédio, medo, sofrimento, agonia e ajustamentos criativos disfuncionais etc. Implica, sobretudo, uma reflexão acerca do funcionamento saudável de uma pessoa, para que ela possa encontrar o sentido e a força necessários para mantê-la viva e, assim como Young \& Lester (2001, p. 68) mencionam em seu interessante artigo Gestalt therapy approaches to crisis intervention with suicidal clients, "Para Perls, o caminho para a saúde psicológica encontra-se na integração harmoniosa de todos os aspectos do self. A terapia foca na ampliação da awareness e em facilitar a confiança do cliente na sabedoria da autorregulação organísmica”.
A Gestalt-terapia não acredita em correção e adequação dos comportamentos dos clientes e, se alguém pensa na morte como solução para seu desespero, vivencia um conflito, portanto, o psicoterapeuta necessita facilitar a reflexão crítica sobre o fluxo de Gestalten interrompido, enfatizando que não se deve tentar minimizar ou eliminar esses conflitos, mas, sim - conforme a proposta de Perls, Hefferline \& Goodman (1951/1997, p. 161) - tratar o conflito como um distúrbio do campo, pois o que se espera, na perspectiva gestáltica, não é a remoção do conflito; é a possibilidade de que um conflito signifique crescimento: "O conflito é uma colaboração que vai além do que se pretende, em direção a uma figura inteiramente nova” (Perls, Hefferline \& Goodman, 1951/1997, p. 164). Desse modo, o imperativo é saber que em todo conflito haverá mudanças e que, quanto maior a crise, mais rápida será a resposta do indivíduo, mesmo que seja pela decisão do suicídio. Cabe ao terapeuta facilitar ao cliente a encontrar respostas para seus conflitos em busca do equilíbrio e da boa forma.

O foco da terapia, nesses casos, pode ser o de identificar por qual(quais) situação(ções) ou conflito(s) o suicídio está sendo visto como solução. Ou seja, a situação que o cliente acredita lhe causar mais conflitos é o foco da psicoterapia, para que se possa conhecer a maneira pela qual esses conflitos afetam a vida do cliente e então ampliar a awareness de suas emoções, dos pensamentos ambivalentes e/ou rígidos e das ações desse indivíduo em direção à satisfação das necessidades dele, que são, muitas vezes, impulsivas. Além disso, a psicoterapia pode ser orientada para que a pessoa possa explorar diferentes opções de lidar com a situação que provoca sofrimento, pois aquele que pensa em se matar demonstra intolerância em relação aos conflitos, inabilidade em lidar com a própria ambivalência querer viver-morrer, rigidez ou constrição de pensamentos, impulsividade, ajustamentos criativos disfuncionais, fluxo de Gestalten interrompido, mecanismos defensivos cristalizados, percepção distorcida e fixa, fronteiras de contato extremamente rígidas ou permeáveis, relações pobres ou desvitalizadas, pensamento polarizado, awareness reduzida, autossuporte precário, desespero e desesperança de que a situação não será finalizada ou, ainda, a pessoa parece não vislumbrar outra possibilidade de lidar com o sofrimento, sentindo-se presa e sem saída em uma espiral de pensamentos e sentimentos confusos e recorrentes.

Cabe ressaltar também o que a psicologia da Gestalt ensina: “(...) o todo é diferente da soma das partes: o todo não é nem mais nem maior do que elas” (Frazão, 2013, p. 110). Sendo assim, a pessoa que pensa no suicídio deseja eliminar o sofrimento, parte da existência, mas confunde a necessidade de aniquilar seu sofrimento com auto aniquilar-se, matando o todo.

Vale lembrar que “(...) a mudança ocorre quando uma pessoa se torna o que é, não quando tenta converter-se no 
que não é” (Beisser, 1980, p. 110). Então, o objetivo não seria mudá-la, mas, sim, fazê-la ampliar a awareness, a fim de conquistar o respeito por quem é e perceba suas relações com o meio ambiente. Em alguns casos, o único jeito que a pessoa conseguiu se mostrar e fazer prevalecer sua vontade foi por meio de sua morte.

Qualquer mudança de direção na vida de um indivíduo, uma perda ou separação, pode ser o suficiente para tornar o processo intolerável, confuso e ambíguo. A ambiguidade se instala pelo anseio de transformação e, ao mesmo tempo, pela paralisação de mobilizar a energia para que as mudanças possam acontecer. Por vezes, o sujeito que percebe sua vida sem sentido, apresenta uma visão monocromática e sua vida se torna automatizada na qual a fé se esvai. Ou então, sua fé está justamente no fato de que o suicídio resolverá seu problema. Por isso, destaca-se a importância de se verificar com o cliente suas crenças e fantasias em relação ao ato de se matar. Alvarez (1999, p. 135) pontua “(...) sem os freios da fé, o equilíbrio entre a vida e a morte pode se tornar perigosamente delicado".

Como o profissional pode se colocar a serviço de ser facilitador quando a awareness de uma pessoa se apresenta reduzida? Perls, Hefferline \& Goodman (1951/1997) em Gestalt-terapia afirmam: "Nossa relutância em arriscarmos é obviamente um medo de que, se perdermos isso, não teremos nada; preferimos comida de qualidade inferior a nenhuma comida; habituamo-nos à escassez e à fome” (p. 150, grifo nosso) e, mesmo sem tantas respostas, as autoras desejam arriscar, porque pretendem trazer à luz reflexões sobre o manejo do Gestaltterapeuta diante do suicídio, assim como, apresentar possibilidades para atendimentos em situações de desespero existencial.

Como um dos objetivos da abordagem gestáltica é enriquecer o contato e ampliar a awareness do cliente na relação entre ele, o meio ambiente e o campo, então, como proceder, se o profissional é colocado diante a um indivíduo cuja anedonia o impede de ver e sentir? A resposta vem ao encontro da compreensão do sofrimento e do conflito para a Gestalt-terapia, pois "grandes conflitos verdadeiros" - denominação de Perls, Hefferline \& Goodman (1951/1997) - implicam que o sujeito saia de sua zona de conforto, corra riscos e mude o status quo. No entanto, quando o cliente pensa em cometer o suicídio, a rigidez de pensamento "somente a morte me salvará do sofrimento" ou o pensamento dicotomizado, "se vivo eu me sinto desesperado, talvez morto não me sinta assim" são identificados. Cabe enfatizar a maneira como Perls concebe aquele que comete o suicídio (1975, p. 229) “(...) é exatamente o que uma pessoa suicida é. É um assassino; um assassino que destrói a si mesmo em vez de destruir aos outros. Tanto o assassino quanto o suicida possuem algo em comum: uma impotência para enfrentar a situação; e escolhem a maneira mais primitiva: explosão em violência”
Lilian Meyer Frazão ${ }^{1}$, ensina que o suicida é um "atuante no sentido de acting-out, pois a pessoa tem contato, mas tem awareness de má qualidade. É um contato acting-out que leva a uma ação prematura. Dessa maneira, o indivíduo migra da sensação para a ação, sem passar pela percepção, pela mobilização de energia, pela awareness".

O indivíduo que pensa em se matar geralmente apresenta uma Gestalt cristalizada e fixa. Sua percepção se apresenta distorcida e fixa e a ambivalência de querer viver e morrer se configura, tornando a relação com o mundo e com o outro empobrecida e desvitalizada. $\mathrm{O}$ que acontece nesse momento com o sujeito cuja sensação é a de “nada mudará?". Portanto, o suicídio também pode representar um ato que expressa a dificuldade na relação figura e fundo, na qual uma figura torna-se opaca e sem conexão com fundo, revelando a perda de sentido e dificuldades de se lidar com a impotência diante situações vivenciadas como caos. E, de acordo com a definição do suicídio de Shneidman (1993), adotada neste estudo, o suicídio é um psychache e representa um sofrimento psicológico provocado pela vergonha, culpa, falta de esperança ou, ainda segundo Perls, Hefferline \& Goodman (1951/1997, p. 34): “[...] enquanto confusão, tédio, compulsões, fixações, ansiedade, amnésias, estagnação e acanhamento são indicadores de uma formação figura/fundo perturbada”. Sendo assim, muitos conflitos se referem às situações inacabadas e tais situações afetam o comportamento, porque a pessoa tenta, repetidamente, destruir a situação inacabada adotando os mesmos comportamentos. No entanto, há de se pensar que dificilmente os resultados mudarão se os comportamentos permanecerão os mesmos.

\section{Discussão: proposta do manejo psicoterapêutico em situações de crise}

Sugere-se que o Gestalt-terapeuta trabalhe enfatizando o potencial e os fatores de proteção da pessoa que pensa na morte, a fim de que, ao levantar seus melhores recursos, o cliente possa descobrir e realizar novos ajustamentos criativos. É de suma importância a averiguação de todas as fantasias associadas ao suicídio, sejam elas em relação ao que imagina que acontecerá quando ela se matar ou ao impacto do suicídio nos que ficarão.

No que se refere aos fatores de proteção, torna-se imprescindível pontuar que o Gestalt-terapeuta tem como direção em seu trabalho o fortalecimento do cliente nos seguintes aspectos: ampliação de awareness para que, a partir dela (awareness com maior qualidade), o contato seja enriquecido, a fluidez da relação entre a figura e fundo possa acontecer, os ajustamentos criativos possam se tornar funcionais e as fronteiras, plásticas e permeáveis.

\footnotetext{
Comunicação pessoal em 11 de fevereiro de 2011.
} 
É importante verificar e perceber os fatores predisponentes levantados por especialistas que recomendam ação imediata nas seguintes situações: Quando alguém ameaça se machucar ou procura métodos para se matar: buscando o acesso às medicações, armas ou quando a pessoa fala ou escreve sobre morte, morrer ou suicídio. Nesse sentido, deve-se avaliar o grau do comportamento suicida.

Alguns sinais a serem observados são: A presença de um plano; a falta de esperança; depressão; fúria, raiva, sentimento de vingança; participação de atividades de alto risco, aparentemente sem pensar nas consequências; sentimentos de estar encurralado, não vislumbrando saída; aumento do uso de álcool ou drogas; afastamento dos amigos, da família e da sociedade; ansiedade, agitação, dificuldades para dormir ou dormir o tempo inteiro; alterações súbitas de humor e falta de sentido para viver (Quinnet, 2008, p. 3).

Outra indicação a ser destacada são as tentativas prévias, assim como Jamison (2010, p. 25) afirma: "Ainda assim, uma tentativa continua sendo o único e melhor provisor do suicídio, e esses números são motivo de preocupação grave”. A combinação de tentativas prévias com a presença de algum transtorno mental grave podem aumentar os riscos de suicídio (Harris \& Barraclough, 1997). Além disso, conhecer os fatores de risco supracitados abarca somente uma parte de todo o trabalho com o suicídio, pois é importante salientar que prevenção não significa previsão, pois como dito anteriormente, o suicídio é multifatorial.

Para o acompanhamento após uma tentativa indicamos: (1) reavaliar a situação em 24 horas, garantindo que a pessoa esteja em um ambiente seguro e protegido; (2) gerenciar, orientar e acompanhar os familiares; (3) solicitar que os familiares, amigos e/ou acompanhantes fiquem próximos do indivíduo que tentou o suicídio depois da alta hospitalar, evitando que ele fique sozinho; (4) levantar possibilidades e investigar se o ambiente onde a pessoa se encontra apresenta perigos (quarto com sacada, medicamentos acessíveis, por exemplo); (5) munir-se de planos para uma rápida ação, caso a ansiedade, a ideação e os sintomas aumentem; (6) entrar em contato com os profissionais envolvidos com o cliente (por exemplo, psiquiatras); (7) acolher a família.

Salientamos que para se trabalhar com o suicídio são necessários o respeito pela vida e fé na vida, a confiança na autorregulação e a crença no autossuporte. Em outras palavras, acredita-se que o manejo psicoterapêutico pode ser favorecido pela crença de que aquele que se propõe a compreender os fenômenos humanos, o profissional da saúde, necessita perceber os fenômenos da vida com olhos ingênuos, tolerando inclusive a falta de fé do outro com quem se relaciona. Além disso, enfatiza-se a importância da persistente curiosidade pelos assuntos que se referem à vida e à morte do ser que é humano e o estar disponível, presente e atento para o outro.
Também é necessário que cada terapeuta examine suas crenças e seus sentimentos relacionados ao suicídio, pois eles certamente estarão presentes no "entre" do processo terapêutico, e conhecê-los previamente pode ajudar o terapeuta a descobrir suas potencialidades e dificuldades ao lidar com o cliente em crise suicida, pois, se acredita que a pior hora para se descobrir que não se consegue lidar com pessoas que pensam e/ou cometem o suicídio é em meio à crise suicida.

Outro aspecto fundamental é a valorização da escuta do quanto alguém pode suportar seu sofrimento, sendo necessário, algumas vezes, o envolvimento de outros profissionais, tais como psiquiatras. Então, o psicoterapeuta deve preocupar-se em aprimorar a comunicação sobre a intenção de o indivíduo cometer o suicídio e verificar, principalmente, os aspectos relacionados à autopreservação desse indivíduo. É importante falar, discutir sobre o plano de suicídio, pois, ao compartilhar a maneira como, quando e porque pensa em morrer pode ser uma maneira de prevenir o suicídio acolhendo seu solitário sofrimento. O terapeuta não deve ter receio de perguntar sobre o suicídio para um cliente; na dúvida, indica-se que sempre pergunte. Deve-se salientar que, de acordo com Quinnet (2008, p. 8), às vezes, pessoas que pensam no suicídio concordam em pedir ajuda, mas não a procura e mesmo que concordem com a necessidade, resistem à ideia de procurar ajuda, pois quanto menos esperançosos e mais se sentindo sem saída maior será a dificuldade para aceitarem ajuda.

Dessa maneira, o caminho adotado no trabalho com aqueles que pensam em cometer suicídio ou tentaram, mas a morte não foi consumada, é levantar as experiências que façam com que elaborarem as próprias perguntas. Barry Stevens (1977, p. 267) diz que "[...] o problema delas [pessoas] é pensar e que o que elas precisam fazer é prestar atenção ao que fazem, no sentido de ter presente, explorar, observar. Nós enchemos as nossas vidas com uma quantidade extraordinária de pressuposições”, por esse motivo, nós, profissionais, devemos, investigar o máximo possível para evitar as pressuposições (tanto do cliente como do terapeuta) e como ensinam Perls; Hefferline \& Goodman (1997, p. 89) "O objetivo da terapia é superar a solidão, restaurar a autoestima e realizar a comunicação sintáxica”.

\section{Em relação à pessoa que pensa no suicídio}

O suicídio pode ser interpretado como um gesto de desespero que mostra uma esperança e um desejo de que tudo poderia ser diferente. Ter fé na vida proporciona a crença de que somos seres constituídos por uma gama de estímulos, compreensões, articulações e, por esse motivo, precisamos abrir caminhos para a vida e para a manutenção satisfatória do nosso viver. E assim como Juliano (1999) ensina, “Queremos, em síntese, vitalizar o 
fluxo perceptual. Em contrapartida, ressalta-se que, em Gestalt-terapia, tudo depende do grau e aquele que tem clareza do que quer e se mobiliza para a ação, amplia seu contato e, ao contrário, aquele que percebe sua necessidade, porém não mobiliza sua energia para ir ao encontro da satisfação, interrompe seu fluxo de destruição de Gestalt”. Nesse sentido, realiza-se uma aproximação entre alguns dos mecanismos neuróticos e o suicídio para que o profissional possa ter uma ampliação de seu manejo, salientando-se que as propostas terapêuticas apresentadas a seguir, resultaram da prática nos atendimentos com indivíduos que apresentavam ideações suicidas e/ou clientes cujo suicídio aconteceu de fato.

É necessário que o profissional tolere a falta de sentido do outro. Quando a tolerância do psicoterapeuta é pequena para aceitar o suicídio sem investigar efetivamente o significado da morte para o cliente, ou seja, quando não tenta compreender a motivação pela qual a morte é tão desejada ou, então, não consegue nem lidar com esse assunto de maneira aberta, o trabalho apresenta dificuldades.

A projeção emerge quando a pessoa busca outra maneira de viver, talvez com menos sofrimento e coloque na fantasia de que sua vida seria diferente se morresse e, como afirma Fukumitsu (2011, p. 92), "Projeta na morte a possibilidade que não consegue em vida”. Enfatiza-se que uma das compreensões que se tem sobre o suicídio é que ele representa um pedido interrompido de vida e não de morte e, por isso, torna-se válido levantar o que o cliente que pensa na morte como solução, o que deseja transmitir. Nesse sentido, a questão norteadora seria: a pessoa com o comportamento suicida deseja - se é que deseja - transmitir o quê?

A retroflexão cristalizada é percebida quando na impossibilidade de lidar com o meio ambiente, o sujeito investe sua energia em autoaniquilamento e a falha no processo de autorregulação se torna perceptível. O psicoterapeuta pode, então, estimular a capacidade de escolhas do cliente, no sentido de fortalecer seu autossuporte (autoapoio), pois a pessoa que prefere a morte à vida pode estar oferecendo indícios de que seu autossuporte é precário, uma vez que não consegue encontrar recursos para enfrentar o sofrimento. Concomitantemente, outra estratégia é encorajar o cliente a não reprimir seus sentimentos, sobretudo a raiva, pois, se for reprimido, a tendência é a de que o cliente atue direcionando a energia agressiva para si.

A proflexão é percebida quando o indivíduo deseja se vingar de outra ou quando, por meio de sua morte, ameaçar o outro para que a situação se torne como desejava. Exatamente por esse motivo, para evitar que sua manipulação e necessidade de vingança retornem para o outro, tornando-o vítima de seu ato algoz, discutir com o cliente sobre sua ideação suicida é essencial, assim como Young \& Lester (2001, p. 68) afirmam: clientes precisam falar abertamente sobre seus pensamentos e sentimen- tos suicidas, enquanto podem se sentir seguros e aceitos. Muitos clientes oferecerão fortes dicas e pistas para testar se o psicoterapeuta tem a coragem e está atento para discutir sobre o suicídio. Alguns precisam apenas disso - tempo com alguém acolhedor e respeitoso, que se dispõe, em presença, falar sobre seus pensamentos suicidas e sobre seu desespero.

A utilização da confluência como manejo é ressaltada quando o psicoterapeuta fala para o cliente que expõe suas ideações suicidas: "Eu quero que você viva; gostaria que você soubesse que pode contar comigo para superar isso - juntos". No entanto, como dito anteriormente, tudo depende do grau: a confluência tem suas reverberações quando o desejo do cliente é buscar fantasiosamente um apoio externo que possa salvá-lo. Intensificar a empatia e não mais a apatia: somos seres relacionais e, portanto, faz total diferença quando, mediante o sofrimento, o outro se mostra disponível. O terapeuta, portanto, deve ficar atento e perceber o grau de confluência dessa relação e usá-la a serviço do cliente, já que muitas vezes, clientes com esse grau de comprometimento e crise tendem a despertar no terapeuta um sentimento profundo de necessidade de cuidado, e o terapeuta pode ficar "preso" a essa necessidade do cliente de ser cuidado e do terapeuta de cuidar.

O psicoterapeuta pode investigar o que provoca no cliente o sentimento de pertencimento. Por exemplo: uma cliente que menciona que a única coisa que a deixa feliz é ver seu neto crescendo cada vez mais saudável e que se sente feliz por poder acompanhar e cuidar dele - é dessa relação entre avó e neto que o sentimento de pertença poderá ser enfatizado. Nessa mesma direção, a descoberta de novas capacidades de se comunicar, aumentando as redes de apoio, relacionamentos interpessoais são outros recursos que podem auxiliar na busca do sentido de vida.

A confluência é evidenciada quando a pessoa parece já se sentir morta em vida e morrer significaria identificar-se em totalidade com a parte já morta, ou seja, a parte passa a ser o todo, pois para destruir uma parte do sofrimento, mata-se o todo. Sendo assim, o Gestaltterapeuta precisa facilitar ao cliente s "diferenciar entre o óbvio e o que é fantasia ou imaginação” (Stevens, 1977, p. 241).

Outro ponto a ser levantado na compreensão da confluência gestáltica é o fato do indivíduo ser parte de um todo que está inserido em uma história familiar que, por sua vez influencia sua maneira de ser e delimitam os papéis e funções de cada membro familiar. Segundo o aporte gestáltico pode-se compreender que o ato de se matar representa uma morte que acontece na família ou da família, pois o indivíduo que apresenta o comportamento suicida está inserido em um sistema familiar sendo que, por vezes, o suicídio representa somente a ponta do iceberg de uma dinâmica familiar disfuncional. Dessa maneira, a pessoa que comete ou tenta o suicídio pode 
carregar o peso da morte e o estigma de ser considerado o doente da família, enquanto outros assumem o papel de saudáveis. Portanto, há de se lembrar de que não é somente o indivíduo que apresenta ajustamentos criativos disfuncionais, mas, sim, provavelmente, a família também faz parte da compreensão da disfuncionalidade dos comportamentos autodestrutivos.

Ainda na tentativa de acolher o sofrimento e direcionar o sujeito que se encontra em desespero, Quinnet (2008, p. 9) nomeia de fase de persuasão e orienta que o profissional: persista na afirmação de que o suicídio não é a melhor alternativa e que alguma alternativa melhor pode ser encontrada; foque na solução dos problemas e não na solução do suicídio; acolha respeitosamente o sofrimento, mas oferecendo alternativas além da morte; ofereça esperança de qualquer jeito.

Sintetizando: as intervenções em crise sugeridas, segundo nossa atuação clínica e revisão de literatura são: (1) reconhecer a ideação suicida, levantando os fatores de risco; (2) explorar a intenção do suicídio, perguntando, por exemplo: Você pensa em se matar? Está tão difícil que você quer acabar com sua vida?; (3) explorar o plano suicida, perguntando diretamente: Como você pensa em se matar? Você já tem um plano? Por que meio deseja se matar? Data?; (4) fazer uma avaliação compreensiva dos riscos de suicídio, para tentar entender o sentido do ato; (5) explorar sentimentos tais como, raiva, tristeza, desejo de vingança; (6) envolver a família, se necessário; (6) focar na awareness da ambivalência entre querer morrer e querer viver de outra maneira; (7) reconhecer e confirmar o embate da luta psicológica e aqui, destacando-se a importante influência da relação dialógica na Gestaltterapia, na qual "É no evento do inter-humano que ocorre o encontro dialógico, caracterizado pela reciprocidade das partes que se relacionam, pela presença confirmadora da pessoa do outro, pela abertura para a totalidade do ser do outro, que de outra maneira, permaneceria desconhecida" (Cardoso, 2013, p. 64); (8) acolher o sentimento de impotência e solidão; (9) tentar se manter calmo, adotando uma postura de acolhimento e escuta; (10) compartilhar a preocupação para com o cliente e com a possibilidade de ele se matar, dizendo: Gostaria de ter a permissão de saber sobre seu desespero antes que você tente se matar; (11) explorar e levantar, com o cliente, as opções; (12) estabelecer um contrato não suicida, afirmando, por exemplo: Você precisa me ajudar a ajudar você, incentivando o cliente a procurar pessoas que possam acolhê-lo no momento de crise. Vale salientar que esse contrato só funciona na presença de aliança terapêutica favorável, do contrário, tornam-se somente palavras. Caso o cliente não aceite procurar ajuda durante a crise, cabe ao terapeuta retomar a combinação do contrato terapêutico no qual foi acordado que o sigilo poderia ser quebrado em situações de risco de vida; (13) documentar todos os contatos fora do combinado, crises e manejo terapêutico.
Não se pode ficar alheio ao comportamento suicida de um cliente, o desespero existencial que envolve o suicídio deve ser acolhido e trabalhado pelo terapeuta, com respeito, calma e ética. Existem diversas maneiras de fazer isso, assim como existem os mais diversos tipos de clientes. Caberá ao terapeuta definir o melhor manejo para cada caso.

Um cliente com comportamentos suicida desperta no terapeuta diversos questionamentos relacionados às suas responsabilidade e competência. Se o profissional não tiver consciência de que sua tarefa não é a de salvar vidas, mas sim, o de facilitar a ampliação das possibilidades existenciais para que o cliente lide com seu desespero, pode sentir impotência, e por consequência, fugirá do acolhimento ao sofrimento, levando-o a optar pelo encaminhamento do cliente e ao distanciamento da possibilidade de ser o cuidado na relação psicoterapêutica um fator de proteção para comportamentos suicidas.

Alguns profissionais da saúde não querem sequer discutir sobre o assunto. No entanto, considera-se a necessidade de se destituir o lugar do tabu do suicídio, pois deve-se lembrar que aquele que pensa em se matar é antes de tudo uma pessoa em sofrimento intenso e que o suicídio pode ser prevenido, se talvez, a pessoa for acolhida. Sendo assim, o objetivo deste estudo foi o de oferecer possibilidades de manejo, promover e incentivar a discussão sobre o assunto, principalmente em cursos de graduação e de formação de profissionais da saúde.

\section{Referências}

Beck, A. T., Resnik, H. L., \& Lettieri, D. J. (1974). The prediction of suicide. Philadelphia, PA: Charles Press.

Beisser, A. R. (1980). A teoria paradoxal da mudança. In J. Fagan \& I. L. Shepherd (Orgs.), Gestalt-terapia: teorias, técnicas e aplicações. Rio de Janeiro: Zahar Editores.

Cardoso, C. L. (2013). A face existencial da Gestalt-terapia. In L. M. Frazão \& K. O. Fukumitsu (Orgs.), Gestalt-terapia Fundamentos Epistemológicos e Influências Filosóficas - Vol. 1 (pp. 59-75). São Paulo: Summus Editorial.

Chiles, J. A., \& Strosahl, K. D. (2005). Clinical Manual for Assessment and Treatment of Suicidal Patients: American Psychiatric Publishing.

Frazão, L. M. (2013). Um pouco da história... um pouco dos bastidores. In L.M. Frazão \& K.O. Fukumitsu (Org.), Gestalt-terapia - Fundamentos Epistemológicos e Influências Filosóficas. (Vol. 1, pp. 11-23). São Paulo: Summus Editorial.

Fukumitsu, K. O. (2011). Suicídio e Gestalt-terapia. São Paulo: Editora Digital Publish \& Print.

Harris, E. C., \& Barraclough, B. (1997). Suicide as an outcome for mental disorders. A meta analysis. The British Journal of Psychiatry, 170, 205-228. 
Juliano, J. C. (1999). A arte de restaurar histórias: o diálogo criativo no caminho pessoal. São Paulo: Summus Editorial.

Perls, F. (1988). A abordagem gestáltica e testemunha ocular. Rio de Janeiro: LTC (Original publicado em 1975).

Perls, F.; Hefferline, R. \& Goodman, P. (1995) Gestalt-terapia. São Paulo: Summus Editorial (Original publicado em 1951).

Quinnet, P. (2008). QPR Gatekeeper Enhanced Course Review. Washington: The QPR Institute.

Shneidman, E. S. (1993). Suicide as psychache. The Journal of Nervous and Mental Disease, 181, 141-147.

Stevens, J. O. (1977). Trabalho Corporal. In Stevens, J. O., Isto é Gestalt. São Paulo: Summus Editorial.

Young, L., \& Lester, D. (2001). Gestalt Therapy Approaches to Crisis Intervention with Suicidal Clients. Oxford Journals - Brief Treatment and Crisis Interventions, 1, 65-74.

Karina Okajima Fukumitsu - Psicóloga, psicoterapeuta, fundadora do Instituto Vita Alere de Prevenção e Posvenção do Suicídio, pós-doutoranda e bolsista da CAPES pelo Programa de Pós-Graduação em Psicologia Escolar e do Desenvolvimento Humano. Endereço Institucional: Avenida Fagundes Filho, 145 sala 96. Vila Monte Alegre. CEP 04304-010. São Paulo/SP. Email: karinafukumitsu@gmail.com

Karen Scavacini - Psicóloga, psicoterapeuta, fundadora do Instituto Vita Alere de Prevenção e Posvenção do Suicídio, especialista em Gestalt-terapia pelo Instituto Sedes Sapientiae, mestre em Saúde Pública na área de Prevenção ao Suicídio e Promoção de Saúde Mental pelo Instituto Karolinska, Estocolmo, Suécia.Email:karen.scavacini@uol.com.br

Recebido em 16.05.13 Primeira Decisão Editorial em 14.08.13 Segunda Decisão Editorial em 28.10.13 Aceito em 04.12 .13 